\title{
Variabilidade espaço-temporal de variáveis climáticas na mesorregião sul do Amazonas
}

Entender a variabilidade espaço-temporal do clima e dos seus elementos é imprescindível para a compreensão de sua dinâmica, seja em escala local, regional ou global. O objetivo deste trabalho foi identificar a dinâmica das variáveis temperatura do ar, umidade relativa do ar, temperatura do ponto de orvalho e precipitação (Ppt) na mesorregião sul do Amazonas (AM). Os dados foram coletados durante 10 anos (abril de 2008 a abril de 2018) nas estações meteorológicas automáticas (EMAS) do Instituto Nacional de Meteorologia (INMET) localizadas nos municípios de Humaitá, Apuí, Manicoré, Boca do Acre e Lábrea, Amazonas, Brasil. A estatística descritiva dos dados baseou-se nas Médias Mensais ( $\bar{X} \mathrm{~m}$ ), Média horária ( $\mathrm{X} D$ ), Erro Padrão (EP), Desvio Padrão (DP), Mediana (MD), Variância (V), Curtose (K) e Assimetria (As). O padrão da precipitação, ao longo do ano, apresentou duas estações climáticas, uma seca, e outra chuvosa além de períodos de transição, responsáveis por $4 \%, 90 \%, 6 \%$, respectivamente, de toda chuva anual. As maiores temperaturas foram às 14 hs e menores às 6 hs. As maiores médias das temperaturas foram registradas na transição inverno-primavera $\left(27,5^{\circ} \mathrm{C}\right)$ e os menores no verão $\left(24,8^{\circ} \mathrm{C}\right)$. Manicoré foi a cidade com as maiores temperaturas. A temperatura do ponto de orvalho registrou os menores valores no período seco (maio a setembro) com média de $17^{\circ} \mathrm{C}$, no qual Manicoré, novamente, apresentou as maiores temperaturas. A umidade relativa do ar obteve suas maiores porcentagens horárias no período noturno. Os meses de julho a setembro registraram o ar mais seco com médias de $70 \%$ de umidade. A cidade de Apuí registrou as maiores médias (90\%). Por fim, o padrão climático registrado na mesorregião sul do Amazonas mostra sazonalidade.

\section{Spatial-temporal variability of the climate variable at the southern mesoregion of Amazonas}

\begin{abstract}
To understand the spatial-temporal variability of the climate, as well as its elements, is crucial to comprehend its dynamics in local, regional or global scale. The main aim of this paper was to identify the dynamic of the air temperature, relative humidity and dew point temperature at the Amazonas Southern Mesoregion. Data have been collected throughout 10 year (April 2008 to April 2018) by the automatic weather stations from the Brazilian Meteorological Institute, placed in the municipality of Humaitá, Apuí, Manicoré, Boca do Acre and Lábrea, Amazonas, Brazil. Data descriptive statistics of hourly and monthly means, standard error median, variance, kurtosis and asymmetry have been used. The highest temperature have been observed between 12 and $14 \mathrm{hs}$ and the lowest between 3 and $6 \mathrm{hs}$. The hottest months were those ones from August to October and Manicoré was the city with the highest air temperature. The dew point temperature registered the lowest values during the dry period (May to September), in average 17 으, in which Manicoré, again, have shown the highest temperatures. The air relative humidity have registered the highest hourly percentages during the nocturnal time. The months from July to September have shown the lowest percentage mean (70\%). The city of Apuí had the highest average among the study cities (90\%). Finally, the climate pattern at the Amazonas Southern region have shown seasonality. The highest air temperature have been observed during the winter and the lowest in the summer season. The other way around was observed to the dew point temperature and to the air relative humidity.
\end{abstract}

Keywords: Climatology; Amazonia; Meteorological variables; Descriptive Statistics.

Topic: Meteorologia, Climatologia e Mudanças Climáticas

Reviewed anonymously in the process of blind peer.
Received: 12/02/2019

Approved: 28/03/2019
Paulo André da Silva Martins

Universidade Federal do Amazonas, Brasil http://lattes.cnpq.br/9094736957370966 martins silvaandre@yahoo.com.br

Carlos Alexandre Santos Querino

Universidade Federal do Amazonas, Brasil http://lattes.cnpq.br/1961496453115559 http://orcid.org/0000-0001-5928-9310

carlosquerino@ufam.edu.br

Marcos Antônio Lima Moura (iD

Universidade Federal de Alagoas, Brasil

http://lattes.cnpq.br/8590684899768285

http://orcid.org/0000-0002-1523-7647

malm@ccen.ufal.br

DOI: 10.6008/CBPC2179-6858.2019.002.0015

\author{
Juliane Kayse Albuquerque da Silva Querino (iD \\ Universidade Federal do Amazonas, Brasil \\ http://lattes.cnpq.br/2063124025919871 \\ http://orcid.org/0000-0003-2312-4818 \\ julianekayse@hotmail.com \\ Aryanne Resende de Melo Moura (iD \\ Universidade Federal do Amazonas, Brasil \\ http://lattes.cnpq.br/1139862885936861 \\ http://orcid.org/0000-0003-4770-1747 \\ aryanneresende.mm@gmail.com
}

\section{Referencing this:}

MARTINS, P. A. S.; QUERINO, C. A. S.; MOURA, M. A. L.; QUERINO, J. K. A. S.; MOURA, A. R. M.. Variabilidade espaço-temporal de variáveis climáticas na mesorregião sul do Amazonas. Revista Ibero Americana de Ciências Ambientais, v.10, n.2, p.169-184, 2019. DOI: http://doi.org/10.6008/CBPC2179-6858.2019.002.0015 


\section{INTRODUÇÃO}

O Amazonas é o maior estado do Brasil $\left(1.570 .746 \mathrm{Km}^{2}\right)$ e todo seu território encontra-se dentro do bioma Amazônico (GALVÃO et al., 2000; SALATI et al., 2006). Ele destaca-se por ter os menores índices de desmatamento entre os estados que compõem a Amazônia Legal. Dentre as macro e microrregiões que compõem o estado, a mesorregião Sul ganha grande destaque quanto ao crescimento agropecuário e populacional (PAVÃO et al., 2014). A mesorregião é composta por dez municípios no qual, ao entorno de suas rodovias, desenvolve-se as principais atividades econômicas como a pecuária, agricultura e extração de madeira (PEDREIRA JUNIOR et al., 2018).

Neste cenário, a mesorregião sul é responsável por grande parte da produção agrícola do estado do Amazonas, com valores médios anuais de 300T de maracujá, 250T de mamão, 20T de goiaba, 540 mil frutos/anual de laranja, 37mil frutos/anual de limão, 4mil frutos/anual de cupuaçu, $854 \mathrm{mil} /$ cachos de banana, 250 mil frutos/ anual de abacaxi, 500T de açaí, 10 mil frutos/ anual de coco, 120T de feijão, 27T de milho, 70T de cacau e 11T de mandioca, além de ser o maior produtor de melancia da região norte com quase 3 milhões de frutos/anuais (IDAM, 2018).

O desenvolvimento agropecuário e madeireiro, fez com que a mesorregião tivesse as maiores taxas de desflorestamento de todo o estado (FEARNSIDE, 2010) causando forte impacto na cobertura do solo (RIVERO et al., 2009; PAVÃO et al., 2014). As mudanças na cobertura do solo podem interferir na transferência de vapor d' água para a atmosfera além de alterar o balanço de radiação e, consequentemente, o balanço energético superficial (MACHADO et al., 2017). Apesar de toda a importância agrícola da mesorregião, estudos envolvendo as variáveis do clima, que interferem diretamente em toda agricultura ainda são escassos, seja ele na forma direta de aquisição de dados meteorológicos ou na modelagem numérica ou estatística. Assim, as alterações da cobertura da superfície podem interferir nos padrões de variáveis climatológicas como precipitação, umidade relativa do ar, temperatura de ponto de orvalho e temperatura do ar de forma local e regional (PAVÃO et al., 2017).

A precipitação forma-se a partir da transferência de calor latente da superfície para a atmosfera (DIAS et al., 2005). No sul do Amazonas a precipitação alcança valores superiores a $2000 \mathrm{~mm}$ anuais. Já a temperatura do ar destaca-se por ser uma das variáveis climáticas mais utilizadas, pois auxilia na compreensão das mudanças nos processos meteorológicos e hidrológicos (NOGUEIRA et al., 2012). Por sua vez, a Umidade relativa (UR) é a quantidade de umidade de uma amostra de ar, ou seja, é a quantidade de umidade que o mesmo volume de ar pode conservar na mesma pressão quando saturado (MENDONÇA et al., 2007). O vapor de água presente na atmosfera para condensar e formar gotículas de chuva precisa resfriar-se a uma temperatura especifica, denominada temperatura de ponto de orvalho (Td) (DIAS et al., 2005) que é definida como a temperatura para a qual a umidade relativa de uma massa de ar em consideração atinge $100 \%$, ou seja, a saturação (DIAS et al., 2005).

Entender os comportamentos climáticos de uma determinada região é de suma importância para o desenvolvimento de diversos setores da atividade humana como o setor agrícola, ambiental e econômico 
(DANTAS et al., 2000; MENDONÇA et al., 2007). Neste contexto, o objetivo deste estudo foi a determinação do comportamento médio mensal e horário da temperatura do ar, do ponto de orvalho, umidade relativa e precipitação na mesorregião sul do Amazonas, afim de contribuir com informações que possam auxiliar nos mais diversos setores como zoneamento agroclimático e planejamento urbano.

\section{METODOLOGIA}

\section{Área de estudo}

O estudo foi realizado na mesorregião sul do Amazonas onde concentram-se dez, dos sessenta e dois municípios do estado do Amazonas, dos quais cinco, Apuí, Boca do Acre, Humaitá, Lábrea e Manicoré (Figura 1) foram analisados nesse estudo, por serem os únicos que possuem estações meteorológicas automáticas. As áreas territoriais dos cinco municípios somadas totalizam $206.215 \mathrm{Km}^{2}$ e estão no quadrante delimitado pelas coordenadas $5^{\circ} 48^{\prime} 32^{\prime \prime} 07^{\circ} 30^{\prime} 22^{\prime \prime} \mathrm{S}$ e $61^{\circ} 18^{\prime} 0^{\prime \prime}$ e $63^{\circ} 01^{\prime} 15^{\prime \prime} \mathrm{W}$ e altitudes que variam entre $32 \mathrm{~m}$ e $127 \mathrm{~m}$. A média populacional varia entre 21,583 hab e 54,907 hab (IBGE, 2018).

O clima da região, segundo a classificação de Köppen, é do tipo Am (monção), com precipitação média anual de 2193,6 mm (ALVARES et al., 2014). O período chuvoso acontece entre outubro e abril, o seco entre junho a agosto, sendo maio e setembro considerados períodos de transição (PEDREIRA JUNIOR et al., 2018).

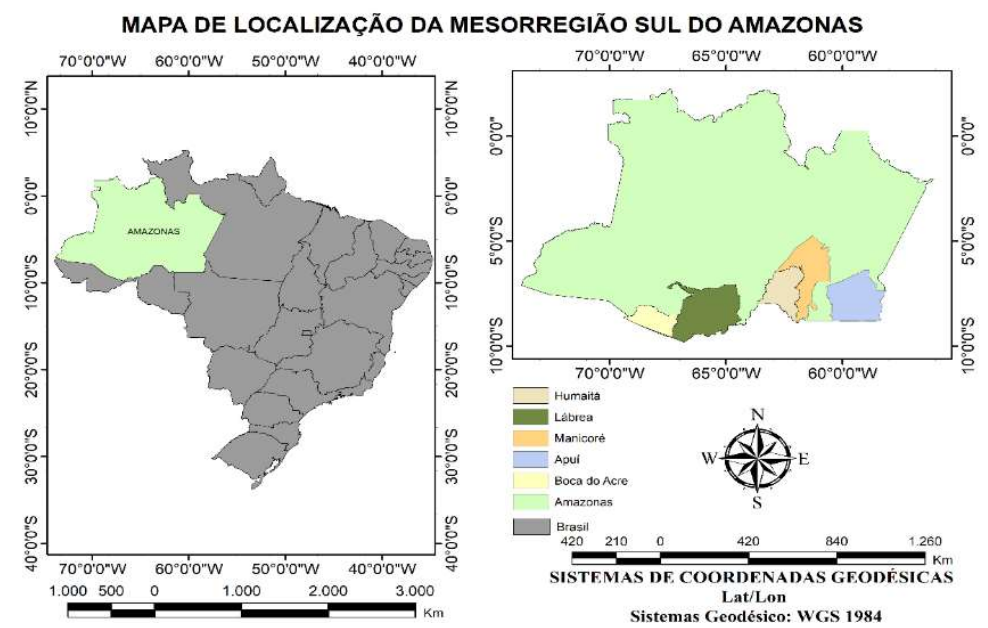

Figura 1: Localização dos municípios de Humaitá, Manicoré, Lábrea, Boca do Acre e Apuí na mesorregião Sul do Amazonas, Brasil.

\section{Dados}

Foram utilizados os dados horários de Temperatura do ar (Tar), Umidade Relativa do Ar (UR) e Temperatura do Ponto de Orvalho (Td) coletados entre abril de 2008 e abril de 2018 (10 anos) por Estações Meteorológicas Automáticas (EMAS), pertencentes ao Instituto Nacional de Meteorologia (INMET), instaladas em cada um dos municípios (Tabela 1). Ressalta-se que Manicoré teve apenas oito anos de dados (2010 - 2018) por ter tido a abertura da estação apenas 2 anos após as demais.

Tabela 1: Informações das estações meteorológicas automáticas do INMET.

\begin{tabular}{|l|l|l|l|l|l|}
\hline Estações & Latitude & Longitude & Altitude (m) & Código (OMM) & Período dos dados \\
\hline Humaitá & $-7^{\circ} 55^{\prime} 25^{\prime \prime}$ & $-63^{\circ} 07^{\prime} 13^{\prime \prime}$ & 54 & 81890 & $2008-2018$ \\
\hline
\end{tabular}




\begin{tabular}{|l|l|l|l|l|l|}
\hline Apuí & $-7^{\circ} 20^{\prime} 54^{\prime \prime}$ & $-59^{\circ} 88^{\prime \prime} 85^{\prime \prime}$ & 157 & 81893 & $2008-2018$ \\
\hline Manicoré & $-5^{\circ} 78^{\prime} 85^{\prime \prime}$ & $-61^{\circ} 28^{\prime} 82^{\prime \prime}$ & 41 & 81810 & $2011-2018$ \\
\hline Boca do Acre & $-8^{\circ} 77^{\prime} 68^{\prime \prime}$ & $-67^{\circ} 33^{\prime} 25^{\prime \prime}$ & 112 & 81927 & $2008-2018$ \\
\hline Lábrea & $-7^{\circ} 26^{\prime} 06^{\prime \prime}$ & $-64^{\circ} 78^{\prime} 85^{\prime \prime}$ & 62 & 81888 & $2008-2018$ \\
\hline
\end{tabular}

\section{Estatística descritiva dos dados}

Os dados de Tar, UR e Td foram analisados estatisticamente através das Médias dos Totais Mensais (Xm), Média dos Totais horários (X̄D), Erro Padrão (EP) (Equação 1), Desvio Padrão (DP) (Equação 2), Mediana (MD) (Equação 3), Variância (V) (Equação 4), Curtose (K) (Equação 5) e Assimetria (As) (Equação 6).

$$
\begin{gathered}
\mathrm{EP}=\frac{\mathrm{DP}}{\sqrt{\mathrm{n}}} \\
\mathrm{DP}=\sqrt{\frac{\sum_{\mathrm{i}}^{\mathrm{n}}=1(\mathrm{Xi}-\mathrm{X})^{2}}{\mathrm{n}-1}} \\
\mathrm{MD}=\frac{(\mathrm{n}+1)}{2} \quad \text { se } \mathrm{n} \text { for ímpar. } \\
\mathrm{MD}=\frac{\left(\frac{\mathrm{n}}{2}\right)+\left(\frac{\mathrm{n}}{2}+1\right)}{2} \quad \frac{\mathrm{K}=\frac{1}{\mathrm{n}} \sum\left[\frac{\mathrm{X} i-\mathrm{X}}{\mathrm{DP}} l^{4}-3\right.}{\mathrm{n}} \quad \text { se } \mathrm{n} \text { for par. } \\
\mathrm{A}_{\mathrm{s}}=\frac{\mathrm{Xi}-\mathrm{X})^{2}}{(\mathrm{n}-1)(\mathrm{n}-2)} \sum\left[\frac{X_{I}-X}{D P}\right]
\end{gathered}
$$

Onde $\mathrm{n}$ é o número de observações, $\mathrm{Xi}$ o valor de temperatura $\left({ }^{\circ} \mathrm{C}\right)$, umidade relativa (\%) e temperatura do ponto de orvalho $\left({ }^{\circ} \mathrm{C}\right)$ observados, e $\mathrm{X}$ é a média dos valores que foram observados das respectivas variáveis meteorológicas.

\section{RESULTADOS}

\section{Precipitação (Ppt)}

Os totais anuais médios de Precipitação (Ppt) foram de 2946,2 mm, 2099,8 mm, 2079,9mm, 2078,3 mm e 1589,0 mm para Manicoré, Lábrea, Humaitá, Boca do Acre e Apuí, respectivamente. A sazonalidade da Ppt apresentou três períodos distintos: o período chuvoso que compreende os meses de outubro a abril; de transição, maio e setembro; e seco, junho a agosto. O período chuvoso foi responsável por quase $90 \%$ de toda precipitação que ocorre no ano, de transição, $6 \%$, e período seco, $4 \%$. O mês mais chuvoso para quatro das cinco cidades foi março com valores acima de $300 \mathrm{~mm}$, à exceção de Apuí que somou $380 \mathrm{~mm}$ em dezembro. Julho e agosto correspondentes ao período seco com totais médios abaixo de $50 \mathrm{~mm}$ (Figura 2).

A Tar em Humaitá teve o máximo de $27^{\circ} \mathrm{C}$ no $4^{\circ}$ quartil e $25,2^{\circ}$ no $1^{\circ}$ quartil. A maior concentração de valores está entre a mediana e o 1 ㅇ quartil. Boca do Acre apresentou comportamento uniforme durante o período de estudo, com a mediana centralizada e valores bem distribuídos entre seus quartis. Manicoré apresentou a distribuição dos valores com máximo de $26,8^{\circ} \mathrm{C}$ e mínimo $25,2^{\circ} \mathrm{C}$ (Figura $3 \mathrm{~A}$ ). 
A Tar nas cidades de Manicoré, Apuí, Boca do Acre e Humaitá obtiveram Desvio Padrão (DP) baixos e Mediana (MD) próximos a média. A série de dados apresentou uma distribuição positiva, pois todos os valores da mediana foram inferiores à média diária (Tabela 2). Todas as cidades apresentam curtose com uma distribuição positiva (curva leptocúrtica).

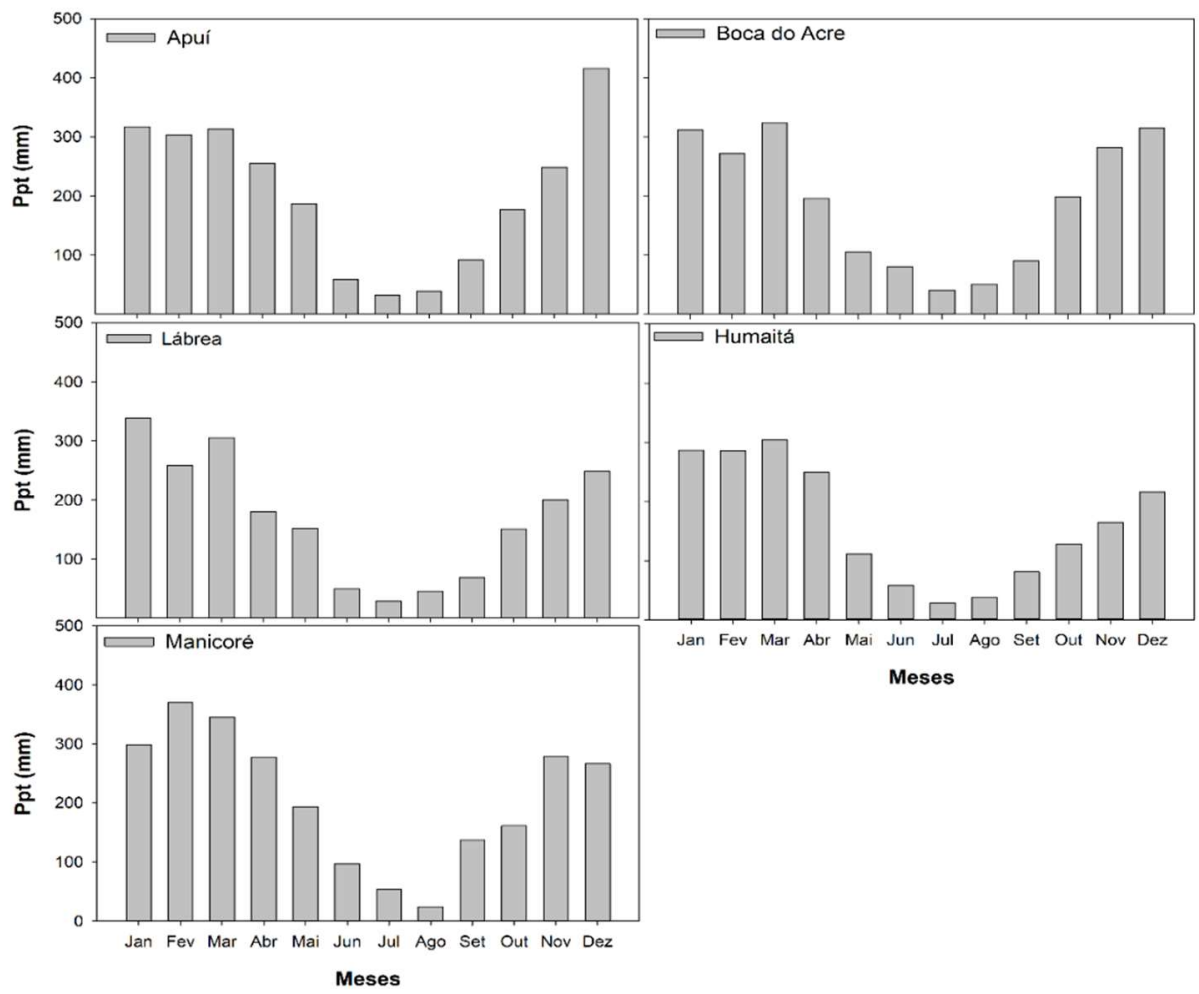

Figura 2: Totais médios mensais da precipitação (Ppt), para o período de 2008 a 2018, para os municípios de Apuí, Boca do Acre Lábrea, Humaitá e Manicoré localizados na mesorregião Sul do Amazonas

\section{Temperatura do ar (Tar)}

As médias máximas mensais de Tar foram registradas em setembro, com valores encontrados em Humaitá $\left(27,5^{\circ} \mathrm{C}\right)$, Lábrea e Manicoré $\left(27^{\circ} \mathrm{C}\right)$ e Boca do Acre $\left(26,5^{\circ} \mathrm{C}\right)$, enquanto Apuí obteve seu maior valor $\left(26,4^{\circ} \mathrm{C}\right)$ em agosto (Figura $\left.3 \mathrm{~B}\right)$. Já os menores valores incidiram em Boca do Acre $\left(24,8^{\circ} \mathrm{C}\right)$, Humaitá e Lábrea $\left(25,5^{\circ} \mathrm{C}\right)$ e Manicoré $\left(26,6^{\circ} \mathrm{C}\right)$, todos no mês de julho.

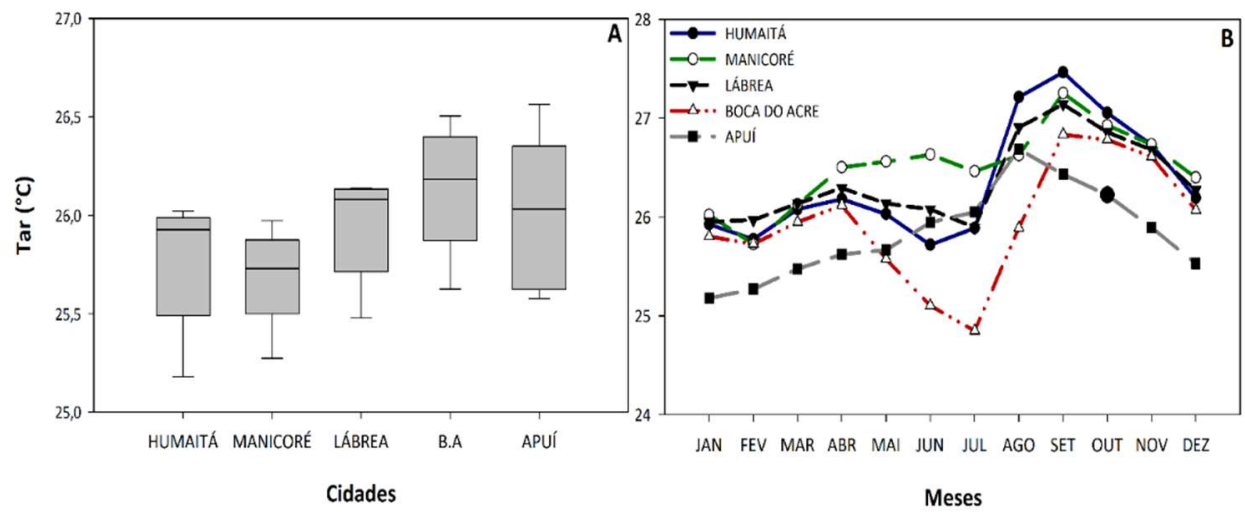

Figura 3: Box Plot da média anual das Temperatura do $\operatorname{ar}\left(\operatorname{Tar}^{\circ} \mathrm{C}\right)(\mathrm{A})$, Médias mensais da temperatura do ar (Tar) (B).

A temperatura média horária do ar (Tar) apresentou um pico máximo de $34,02{ }^{\circ} \mathrm{C}$ em $\mathrm{Apuí,} 33,22{ }^{\circ} \mathrm{C}$ em Lábrea, $32,36^{\circ} \mathrm{C}$ em Boca do Acre, $31,33^{\circ} \mathrm{C}$ em Manicoré e $31,09{ }^{\circ} \mathrm{C}$ em Humaitá. Em todas as cidades, a 
máxima foi registrada às $14 \mathrm{~h}$ e ocorreram agosto (Figura 4 AGO). Os picos mínimos ocorreram às $6 \mathrm{~h}$ no mês de julho, com médias de $19,73{ }^{\circ} \mathrm{C}$ em Boca do Acre, $20,32{ }^{\circ} \mathrm{C}$ em Apuí, $20,98^{\circ} \mathrm{C}$ em Lábrea, $22,81^{\circ} \mathrm{C}$ em Humaitá e $23,38^{\circ} \mathrm{C}$ em Manicoré. As maiores amplitudes térmicas horarias, foram registradas em Humaitá em junho com diferença de $8,27^{\circ} \mathrm{C}$ ao passo que Manicoré registrou $8,2^{\circ} \mathrm{C}$ em março, Lábrea, Boca do Acre e Apuí obtiveram $11,51^{\circ} \mathrm{C}, 12,02^{\circ} \mathrm{C}$ e $13,45^{\circ} \mathrm{C}$ respectivamente no mês de agosto.

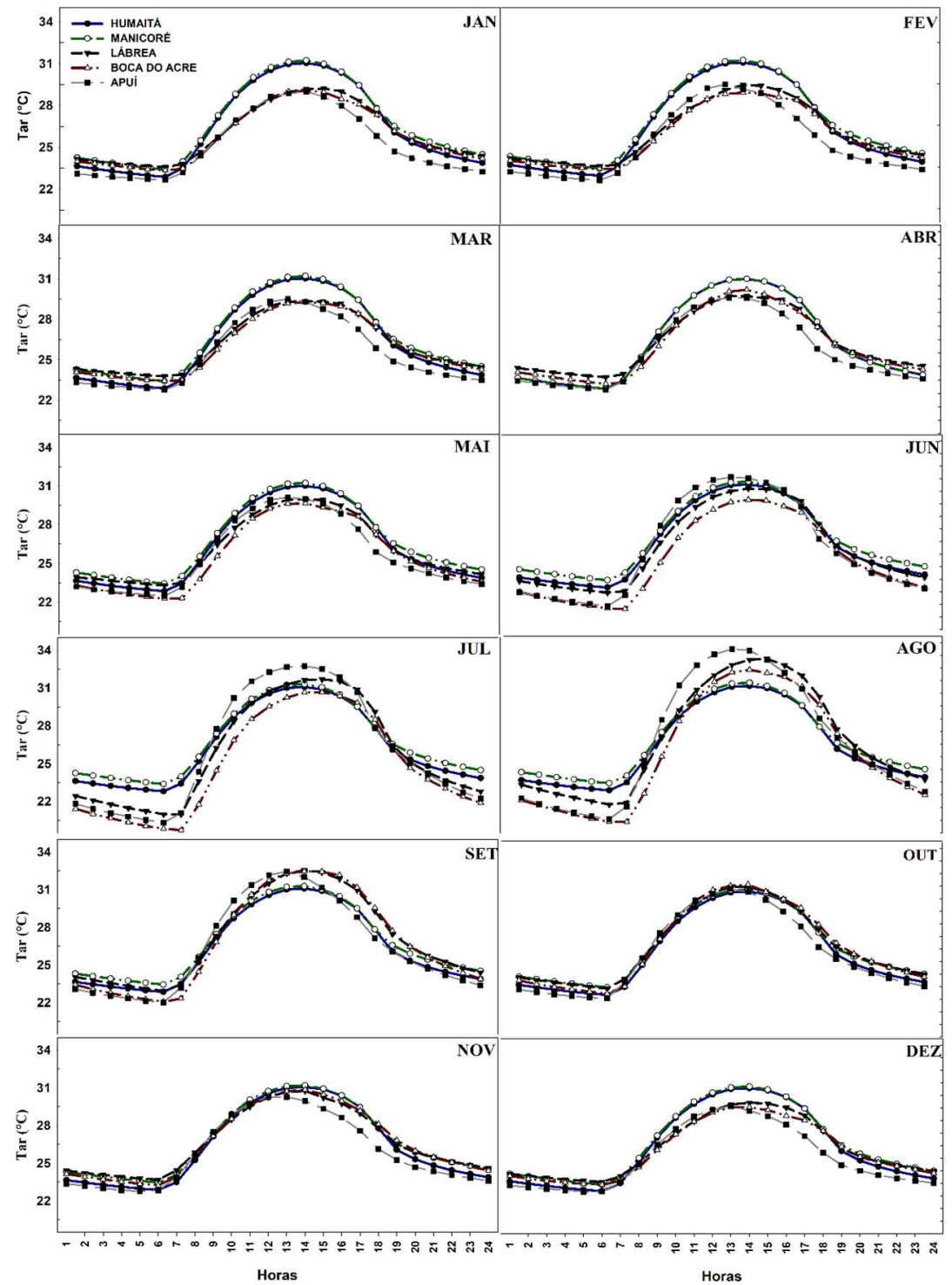

Figura 4: Médias horárias mensais da temperatura do ar (Td) para os anos de 2008 a 2018, para os municípios de Humaitá, Manicoré, Lábrea, Boca do Acre e Apuí, na mesorregião sul do Amazonas, Brasil.

Tabela 2: Estatística descritiva dos dados médios mensais de Temperatura do ar a partir de abril de 2008 a abril de 2018. X̄m: Média Mensal $\left({ }^{\circ} \mathrm{C}\right)$; EP: Erro Padrão; MD: Mediana; DP: Desvio Padrão; V: Variância; K: Curtose; AS: Assimetria.

\begin{tabular}{|c|c|c|c|c|c|c|c|c|c|c|c|c|c|}
\hline & & Jan & Fev & Mar & Abr & Mai & Jun & Jul & Ago & Set & out & Nov & Dez \\
\hline \multirow{7}{*}{ 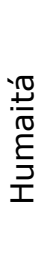 } & $\overline{\mathrm{X}} \mathrm{m}$ & 25,93 & 25,78 & 26,08 & 26,18 & 26,03 & 25,72 & 25,89 & 27,21 & 27,46 & 27,05 & 26,73 & 26,19 \\
\hline & MD & 25,93 & 25,78 & 26,08 & 26,20 & 26,57 & 26,58 & 26,61 & 26,62 & 26,60 & 26,61 & 26,59 & 26,6 \\
\hline & DP & 12,61 & 12,62 & 12,61 & 12,62 & 12,24 & 12,24 & 12,25 & 12,26 & 12,25 & 12,25 & 12,25 & 12,2 \\
\hline & V & 161,24 & 161,33 & 161,26 & 161,36 & 151,79 & 151,90 & 152,04 & 152,25 & 152,16 & 152,14 & 152,11 & 152,0 \\
\hline & EP & 0,04 & 0,04 & 0,04 & 0,04 & 0,04 & 0,04 & 0,04 & 0,04 & 0,04 & 0,04 & 0,04 & 0,0 \\
\hline & $\mathrm{K}$ & 1,51 & 1,51 & 1,51 & 1,52 & 1,37 & 1,36 & 1,86 & 1,96 & 2,00 & 2,01 & 2,02 & 2,0 \\
\hline & As & $-0,65$ & $-0,65$ & $-0,66$ & $-0,66$ & $-0,66$ & $-0,67$ & $-0,76$ & $-0,76$ & $-0,77$ & $-0,77$ & $-0,78$ & $-0,8$ \\
\hline \multirow{4}{*}{$\begin{array}{l}\frac{0}{c} \\
\frac{.}{\pi} \\
\frac{\pi}{2}\end{array}$} & $\overline{\mathrm{X}} \mathrm{m}$ & 26,02 & 25,73 & 26,13 & 26,50 & 26,56 & 26,63 & 26,46 & 26,62 & 27,25 & 26,93 & 26,73 & 26,40 \\
\hline & $M D$ & 26,85 & 26,85 & 26,86 & 26,87 & 26,89 & 26,90 & 26,93 & 26,94 & 26,94 & 26,93 & 26,91 & 26,86 \\
\hline & $\mathrm{DP}$ & 1,98 & 1,98 & 2,00 & 2,00 & 2,00 & 2,00 & 2,02 & 2,03 & 2,00 & 2,00 & 2,00 & 1,99 \\
\hline & $\mathrm{V}$ & 4,64 & 4,66 & 4,71 & 4,70 & 4,71 & 4,71 & 4,76 & 4,82 & 4,71 & 4,69 & 4,68 & 4,63 \\
\hline
\end{tabular}




\begin{tabular}{|c|c|c|c|c|c|c|c|c|c|c|c|c|c|}
\hline & EP & 0,04 & 0,04 & 0,04 & 0,04 & 0,04 & 0,04 & 0,05 & 0,05 & 0,04 & 0,04 & 0,04 & 0,04 \\
\hline & $\mathrm{K}$ & 0,29 & 0,30 & 0,33 & 0,36 & 0,36 & 0,36 & 0,48 & 0,49 & 0,35 & 0,35 & 0,35 & 0,40 \\
\hline & As & $-0,18$ & $-0,18$ & $-0,19$ & $-0,20$ & $-0,20$ & $-0,21$ & $-0,27$ & $-0,28$ & $-0,23$ & $-0,24$ & $-0,23$ & $-0,25$ \\
\hline \multirow{7}{*}{ 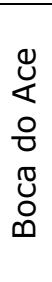 } & $\bar{X} m$ & 25,80 & 25,73 & 25,95 & 26,12 & 25,58 & 25,11 & 24,85 & 25,89 & 26,84 & 26,78 & 26,61 & 26,07 \\
\hline & $\mathrm{MD}$ & 26,20 & 26,20 & 26,21 & 26,20 & 26,22 & 26,22 & 26,24 & 26,25 & 26,26 & 26,26 & 26,25 & 26,24 \\
\hline & DP & 9,96 & 9,94 & 9,91 & 9,89 & 9,87 & 9,86 & 9,83 & 9,84 & 9,84 & 9,83 & 9,81 & 9,77 \\
\hline & $\mathrm{V}$ & 99,65 & 99,11 & 98,55 & 98,27 & 97,86 & 97,61 & 97,06 & 97,18 & 97,11 & 97,00 & 96,66 & 95,83 \\
\hline & EP & 0,05 & 0,05 & 0,05 & 0,05 & 0,05 & 0,05 & 0,05 & 0,05 & 0,05 & 0,05 & 0,05 & 0,05 \\
\hline & $\mathrm{K}$ & 3,27 & 3,27 & 3,29 & 3,27 & 3,29 & 3,18 & 3,19 & 3,09 & 3,14 & 3,16 & 3,20 & 3,23 \\
\hline & As & $-1,15$ & $-1,15$ & $-1,15$ & $-1,15$ & $-1,16$ & $-1,15$ & $-1,18$ & $-1,15$ & $-1,16$ & $-1,17$ & $-1,18$ & $-1,18$ \\
\hline \multirow{7}{*}{ 高 } & $3 \times 1$ & 25,18 & 25,27 & 25,48 & 25,62 & 25,67 & 25,95 & 26,05 & 26,69 & 26,43 & 26,22 & 25,90 & 25,53 \\
\hline & 02 & 26,00 & 26,01 & 26,02 & 26,03 & 26,04 & 26,06 & 26,00 & 26,00 & 25,99 & 25,98 & 25,98 & 25,98 \\
\hline & 0 & 5,37 & 5,76 & 6,26 & 6,68 & 7,06 & 7,37 & 7,87 & 8,03 & 8,03 & 8,01 & 7,98 & 7,94 \\
\hline & $<$ & 31,26 & 34,83 & 40,30 & 45,36 & 50,24 & 54,58 & 62,46 & 65,02 & 64,89 & 64,60 & 64,19 & 63,44 \\
\hline & $0 \mathrm{~m}$ & 0,04 & 0,04 & 0,04 & 0,04 & 0,04 & 0,04 & 0,04 & 0,04 & 0,04 & 0,04 & 0,04 & 0,03 \\
\hline & $\pi$ & 0,40 & 0,41 & 0,40 & 0,40 & 0,40 & 0,40 & 0,38 & 0,38 & 0,41 & 0,41 & 0,41 & 0,42 \\
\hline & As & $-0,41$ & $-0,41$ & $-0,41$ & $-0,42$ & $-0,42$ & $-0,43$ & $-0,40$ & $-0,40$ & $-0,41$ & $-0,40$ & $-0,40$ & $-0,40$ \\
\hline \multirow{7}{*}{ 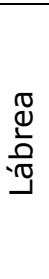 } & $\overline{\mathrm{X}} \mathrm{m}$ & 25,95 & 25,97 & 26,14 & 26,30 & 26,14 & 26,08 & 25,89 & 26,91 & 27,14 & 26,86 & 26,68 & 26,27 \\
\hline & $M D$ & 26,56 & 26,58 & 26,58 & 26,58 & 26,59 & 26,60 & 26,58 & 26,59 & 26,59 & 26,59 & 26,60 & 26,59 \\
\hline & $\mathrm{DP}$ & 8,29 & 8,26 & 8,23 & 8,23 & 8,15 & 8,11 & 8,01 & 7,98 & 7,98 & 7,98 & 7,98 & 8,07 \\
\hline & $\mathrm{V}$ & 69,22 & 68,74 & 68,15 & 67,56 & 66,89 & 66,26 & 64,62 & 64,18 & 64,17 & 64,16 & 64,17 & 65,60 \\
\hline & EP & 0,04 & 0,04 & 0,04 & 0,04 & 0,04 & 0,04 & 0,03 & 0,03 & 0,03 & 0,03 & 0,03 & 0,03 \\
\hline & $\mathrm{K}$ & 2,30 & 2,30 & 2,31 & 2,32 & 2,33 & 2,26 & 2,40 & 2,39 & 2,43 & 2,44 & 2,45 & 2,44 \\
\hline & As & $-0,87$ & $-0,87$ & $-0,87$ & $-0,87$ & $-0,88$ & $-0,88$ & $-0,91$ & $-0,90$ & $-0,91$ & $-0,91$ & $-0,91$ & $-0,91$ \\
\hline
\end{tabular}

\section{Umidade relativa (UR)}

A UR também variou acima e abaixo da mediana para Manicoré (Figura 5A). Os valores encontrados nos $1^{\circ}$ e $4^{\circ}$ quartis também foram iguais. Apuí registrou os menores valores de UR com $82,5 \%$ no $1^{\circ}$ quartil e maior parte abaixo da mediana (84\%). Humaitá apresentou os maiores valores médios máximos de UR, com $85,5 \%$ no $4^{\circ}$ quartil, no entanto, concentrou maior parte de seus valores entre $84 \%$ e $85 \%$. A UR média em Boca do Acre variou de $83 \%$ a $85 \%$.

A UR apresentou flutuações no Desvio Padrão (DP) entre os meses do ano, tendo maiores valores no período seco e menores no chuvoso em todos os municípios. As Medianas (MD) foram constantes, mas estiveram quase sempre acima da média. A Variância para Humaitá, em junho, registrou o maior valor 1641, e diferiu dos demais meses que se mostraram similares. No entanto, para as outras cidades, houve similaridade nos valores máximos, ou seja, em todos os meses a variância foi alta. O DP e a V indicam que os dados estão dispersos da média mensal. A série de dados apresentou uma distribuição positiva e negativa, pois as medianas foram inferiores e superiores à média diária (Tabela 3). Todas as cidades apresentaram curtose com distribuição positiva. 


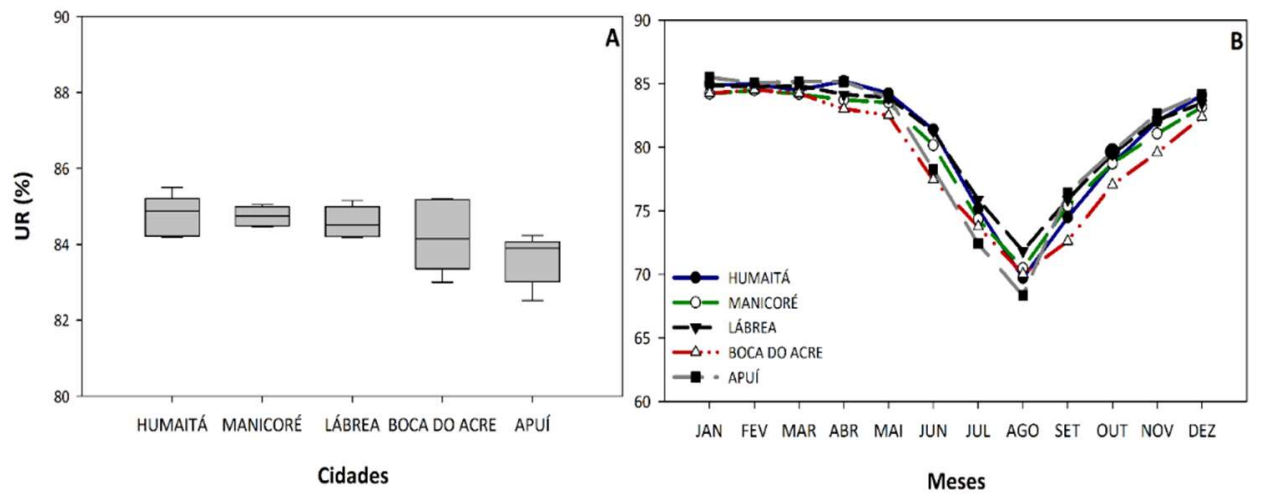

Figura 5: Box Plot da média anual da Umidade relativa (UR\%) (A), e médias mensais da umidade relativa (UR\%) (B), para o período de 2008 a 2018, contemplando os municípios de Humaitá, Manicoré, Lábrea, Boca do Acre e Apuí localizados na mesorregião Sul do Amazonas.

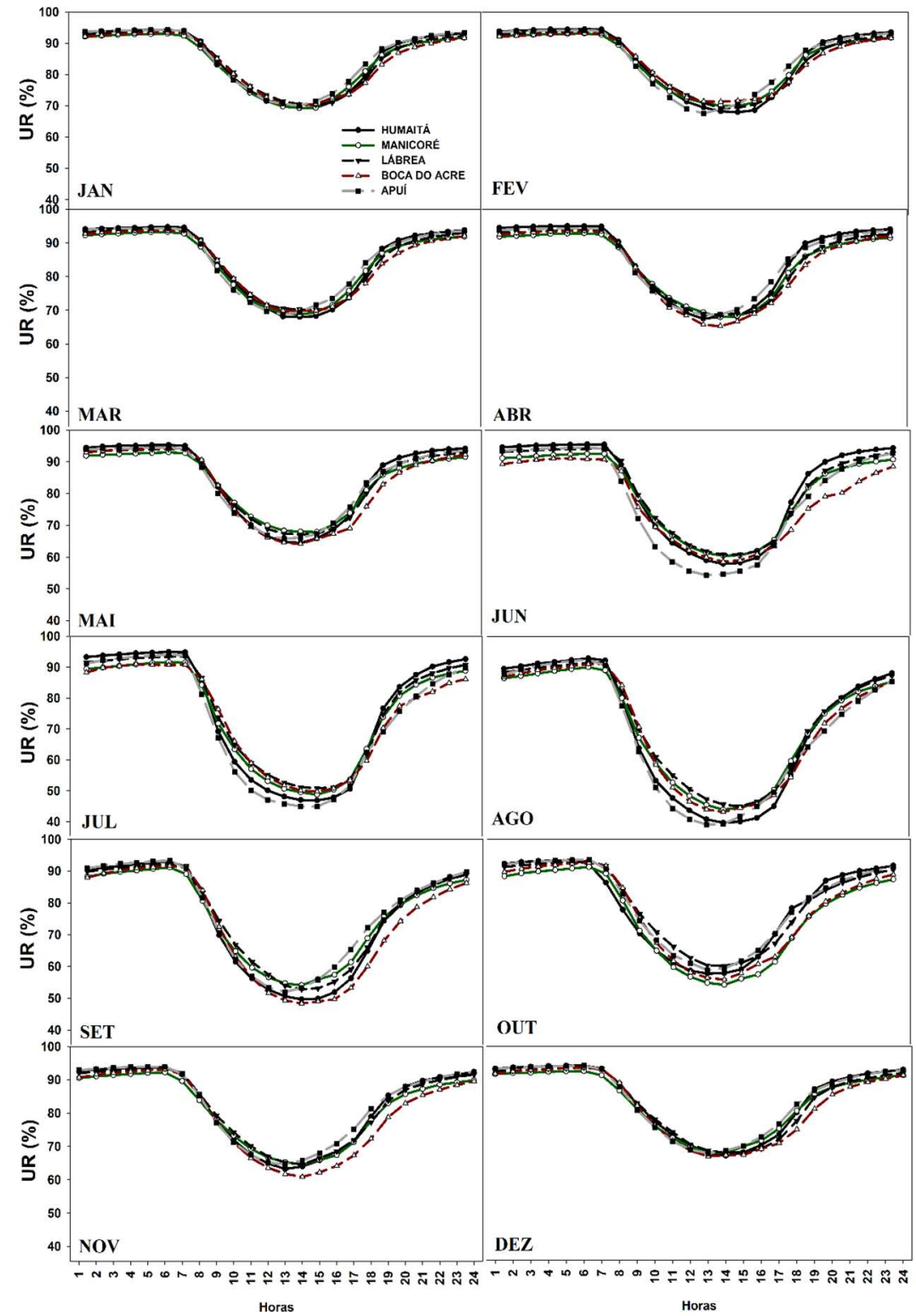

Figura 6: Médias horarias mensais da umidade relativa do ar (UR\%) para os anos de 2008 a 2018, para os municípios de Humaitá, Manicoré, Lábrea, Boca do Acre e Apuí, na mesorregião sul do Amazonas, Brasil.

Os valores máximos médios mensais foram encontrados de novembro a maio, período chuvoso e de transição (Verão-Outono). E obteve 85,3\% em Apuí no mês de janeiro, 85\% em Humaitá, 84\% em Boca do Acre e Manicoré (Figura 5B). Já as menores UR apresentaram-se no período seco (junho - setembro). Apuí 
alcançou os menores valores entre todas as cidades do estudo com $68 \%$, seguida por Humaitá, Boca do acre, Manicoré e Lábrea com 72\%; 73\%; 76\% e 70\% respectivamente, todos os valores ocorreram no mês de agosto.

Tabela 3: Estatística descritiva dos dados médios mensais de Umidade relativa do ar a partir de abril de 2008 a abril de 2018. X̄m: Média Mensal; EP: Erro Padrão; MD: Mediana; DP: Desvio Padrão; V: Variância; K: Curtose; AS: Assimetria.

\begin{tabular}{|c|c|c|c|c|c|c|c|c|c|c|c|c|c|}
\hline & & Jan & Fev & Mar & $A b r$ & Mai & Jun & Jul & Ago & Set & out & Nov & Dez \\
\hline \multirow{7}{*}{ 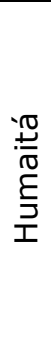 } & $\overline{\mathrm{X}} \mathrm{m}$ & 84,99 & 84,95 & 84,97 & 85,24 & 84,29 & 81,52 & 75,15 & 69,70 & 74,47 & 78,69 & 82,02 & 84,1 \\
\hline & $\begin{array}{l}M \\
D\end{array}$ & 84,69 & 84,69 & 84,56 & 84,77 & 83,94 & 81,15 & 75,40 & 69,42 & 74,17 & 78,67 & 81,90 & 84,0 \\
\hline & DP & 5,62 & 5,49 & 5,71 & 5,02 & 5,64 & 39,95 & 6,43 & 7,72 & 7,84 & 9,93 & 6,44 & 5,6 \\
\hline & $\mathrm{V}$ & 49,69 & 46,82 & 52,53 & 42,05 & 47,62 & $\begin{array}{l}1641,6 \\
9\end{array}$ & 50,65 & 72,87 & 78,10 & $\begin{array}{l}103,9 \\
5\end{array}$ & 59,55 & 47,3 \\
\hline & EP & 0,36 & 0,40 & 0,39 & 0,37 & 0,37 & 0,39 & 0,44 & 0,49 & 0,54 & 0,50 & 0,42 & 0,3 \\
\hline & $\mathrm{K}$ & 2,11 & 1,27 & 1,46 & 1,85 & 4,34 & 7,05 & 15,84 & 2,25 & 1,87 & 2,18 & 1,85 & 2,5 \\
\hline & As & $-0,77$ & $-0,67$ & $-0,63$ & $-0,58$ & $-1,09$ & $-1,20$ & $-1,97$ & 0,07 & $-0,42$ & $-0,67$ & $-0,74$ & $-0,9$ \\
\hline \multirow{7}{*}{$\begin{array}{l}\frac{0}{0} \\
\frac{U}{2} \\
\frac{\pi}{\pi} \\
\Sigma\end{array}$} & $\overline{\mathrm{X}} \mathrm{m}$ & 84,19 & 88,59 & 84,18 & 83,71 & 83,51 & 80,15 & 74,33 & 70,47 & 75,36 & 78,72 & 81,06 & 83,16 \\
\hline & $\begin{array}{l}M \\
D\end{array}$ & 84,10 & 84,21 & 83,94 & 83,44 & 83,38 & 80,04 & 74,48 & 69,92 & 75,50 & 78,35 & 80,83 & 83,17 \\
\hline & DP & 5,08 & 78,22 & 19,94 & 32,02 & 31,71 & 30,69 & 30,71 & 27,56 & 8,76 & 7,48 & 21,87 & 22,17 \\
\hline & $\mathrm{V}$ & 38,08 & $\begin{array}{l}7396,7 \\
4 \\
\end{array}$ & 399,54 & $\begin{array}{l}1035,4 \\
4 \\
\end{array}$ & $\begin{array}{l}1014,4 \\
5 \\
\end{array}$ & 956,07 & 971,26 & 787,93 & 97,48 & 75,80 & $\begin{array}{l}479,3 \\
6 \\
\end{array}$ & $\begin{array}{l}494,3 \\
2 \\
\end{array}$ \\
\hline & EP & 0,37 & 4,74 & 0,38 & 0,39 & 0,37 & 0,44 & 0,61 & 0,60 & 0,65 & 0,55 & 0,53 & 0,42 \\
\hline & $\mathrm{K}$ & 0,17 & 183,52 & 0,39 & 0,14 & 0,56 & 1,07 & 1,81 & 1,09 & 0,45 & 0,29 & 0,32 & 0,56 \\
\hline & As & $-0,39$ & 11,76 & $-0,40$ & $-0,24$ & $-0,29$ & $-0,37$ & $-0,63$ & $-0,10$ & $-0,45$ & $-0,30$ & $-0,42$ & $-0,48$ \\
\hline \multirow{7}{*}{ 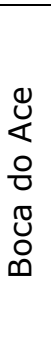 } & $\overline{\mathrm{X}} \mathrm{m}$ & 84,24 & 84,5 & 84,22 & 83,00 & 82,51 & 77,45 & 73,75 & 70,02 & 72,60 & 77,04 & 79,56 & 82,39 \\
\hline & $\begin{array}{l}M \\
D\end{array}$ & 84,33 & 84,4 & 84,13 & 83,08 & 83,00 & 79,65 & 75,38 & 70,46 & 71,83 & 76,94 & 80,19 & 82,88 \\
\hline & $\mathrm{DP}$ & 35,38 & 36,8 & 36,12 & 37,96 & 39,43 & 34,36 & 34,80 & 32,13 & 30,84 & 26,64 & 24,19 & 26,27 \\
\hline & $\mathrm{V}$ & $\begin{array}{l}1318,5 \\
5\end{array}$ & 1403,6 & $\begin{array}{l}1345,2 \\
5\end{array}$ & $\begin{array}{l}1478,3 \\
2\end{array}$ & $\begin{array}{l}1584,2 \\
5\end{array}$ & $\begin{array}{l}1199,3 \\
8\end{array}$ & $\begin{array}{l}1247,3 \\
3\end{array}$ & $\begin{array}{l}1086,4 \\
9\end{array}$ & $\begin{array}{l}998,9 \\
7\end{array}$ & $\begin{array}{l}765,6 \\
6\end{array}$ & $\begin{array}{l}690,1 \\
8\end{array}$ & $\begin{array}{l}810,5 \\
6\end{array}$ \\
\hline & EP & 0,38 & 0,4 & 0,37 & 0,44 & 0,50 & 0,90 & 0,83 & 0,70 & 0,55 & 0,51 & 0,50 & 0,45 \\
\hline & $K$ & 0,46 & 0,3 & 0,63 & 7,10 & 5,39 & 8,72 & 10,25 & 2,88 & 1,07 & 2,75 & 2,50 & 3,02 \\
\hline & As & $-0,49$ & $-0,4$ & $-0,40$ & $-1,28$ & $-1,32$ & $-2,10$ & $-1,92$ & $-0,87$ & $-0,22$ & $-0,61$ & $-0,95$ & $-1,11$ \\
\hline \multirow{7}{*}{ 言 } & $\overline{\mathrm{X}} \mathrm{m}$ & 85,50 & 84,75 & 85,16 & 85,16 & 83,91 & 78,28 & 72,41 & 68,35 & 76,40 & 79,64 & 82,62 & 84,17 \\
\hline & $\begin{array}{l}M \\
D\end{array}$ & 85,46 & 84,83 & 85,06 & 85,21 & 83,79 & 77,48 & 72,40 & 67,35 & 76,15 & 79,38 & 82,67 & 84,29 \\
\hline & $\mathrm{DP}$ & 21,03 & 21,80 & 36,01 & 33,17 & 32,67 & 29,65 & 27,34 & 20,70 & 14,11 & 16,32 & 20,03 & 21,21 \\
\hline & $\mathrm{V}$ & 560,30 & 536,52 & $\begin{array}{l}1343,7 \\
5\end{array}$ & $\begin{array}{l}1154,5 \\
8\end{array}$ & $\begin{array}{l}1124,7 \\
1\end{array}$ & 937,01 & 802,07 & 439,26 & $\begin{array}{l}227,0 \\
3\end{array}$ & $\begin{array}{l}296,7 \\
3\end{array}$ & $\begin{array}{l}472,5 \\
6\end{array}$ & $\begin{array}{l}544,7 \\
8\end{array}$ \\
\hline & EP & 0,33 & 0,36 & 0,36 & 0,35 & 0,36 & 0,41 & 0,49 & 0,56 & 0,48 & 0,44 & 0,39 & 0,35 \\
\hline & $\mathrm{K}$ & 1,31 & 0,73 & 0,96 & 3,58 & 2,40 & 4,42 & 2,13 & 2,44 & 0,84 & 1,76 & 0,89 & 1,05 \\
\hline & As & $-0,71$ & $-0,65$ & $-0,57$ & $-0,99$ & $-0,80$ & $-0,65$ & $-0,39$ & $-0,22$ & $-0,37$ & $-0,61$ & $-0,62$ & $-0,64$ \\
\hline \multirow{7}{*}{ 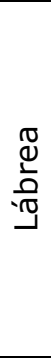 } & $\overline{\mathrm{X}} \mathrm{m}$ & 84,88 & 85,05 & 84,83 & 84,15 & 83,90 & 81,26 & 75,88 & 71,83 & 75,89 & 79,47 & 82,12 & 83,46 \\
\hline & $\begin{array}{l}M \\
D\end{array}$ & 84,60 & 85,27 & 84,58 & 83,90 & 83,85 & 80,88 & 76,02 & 71,88 & 75,35 & 79,02 & 81,83 & 83,38 \\
\hline & DP & 22,32 & 30,57 & 27,12 & 25,13 & 28,45 & 29,82 & 25,51 & 23,95 & 24,47 & 23,24 & 17,50 & 28,21 \\
\hline & V & 557,96 & 987,69 & 764,86 & 650,24 & 838,30 & 936,84 & 678,58 & 592,05 & $\begin{array}{l}608,5 \\
7\end{array}$ & $\begin{array}{l}546,4 \\
5\end{array}$ & $\begin{array}{l}367,3 \\
2\end{array}$ & $\begin{array}{l}864,2 \\
8\end{array}$ \\
\hline & EP & 0,31 & 0,40 & 0,34 & 0,36 & 0,34 & 0,37 & 0,45 & 0,47 & 0,45 & 0,42 & 0,35 & 3,90 \\
\hline & $\mathrm{K}$ & 1,06 & 1,60 & 0,42 & 1,56 & 5,32 & 5,00 & 5,56 & 2,23 & 1,28 & 1,06 & 0,90 & 1,32 \\
\hline & As & $-0,58$ & $-0,87$ & $-0,49$ & $-0,66$ & $-1,31$ & $-1,01$ & $-1,13$ & $-0,60$ & $-0,25$ & $-0,40$ & $-0,46$ & $-0,65$ \\
\hline
\end{tabular}

As médias horárias, apresentaram os picos máximos acima de $90 \%$ nos primeiros 5 meses do ano nos horários entre 1 e $6 \mathrm{~h}$ em todas as cidades estudadas. Humaitá se sobressai, pois apresentou os maiores picos médios com máximo de 95\%, nos primeiros meses do ano também no intervalo de 1 a 6 h (Figura 6). 0 período diurno foi responsável por ter as menores médias horárias, sendo o intervalo entre 11 e $15 \mathrm{~h}$ o responsável 
por $100 \%$ dos menores valores encontrados, chegando a $50 \%$ em Boca do Acre e $55 \%$ em Humaitá ambos em setembro (Figura 6).

\section{Temperatura do Ponto de Orvalho (Td)}

Os dados de Td em Humaitá e Manicoré tiveram comportamento parecidos, com limites inferiores e superiores e mediana próximos variando de $22,8^{\circ} \mathrm{C}$ a $23,6^{\circ} \mathrm{C}$, ambos têm maior concentração de valores abaixo da mediana $23,3^{\circ} \mathrm{C}$. Já os limites superiores e inferiores de Lábrea estiveram entre 23,5 e $23{ }^{\circ} \mathrm{C}$ e apresentou maior concentração de valores entre a mediana e o 1ㅇ quartil (Figura 7A). Boca do acre juntamente com Apuí registraram maiores máximas próximos de $24^{\circ} \mathrm{C}$. Apuí mostrou a maior amplitude de Td entre as cidades máximo de $24^{\circ} \mathrm{C}$ e mínimo de $22,3^{\circ} \mathrm{C}$.

O desvio padrão (DP), Variância (V) e mediana (MD) da Td tiveram comportamentos semelhantes entre as cidades estudadas DP e V demostraram que parte dos dados estão dispersos da média. No entanto, a mediana se mostrou próxima, o que indica uma distribuição positiva (Tabela 4). A curtose foi positiva em todas as cidades (curva leptocúrtica), ou seja, distribuição positiva dos dados.

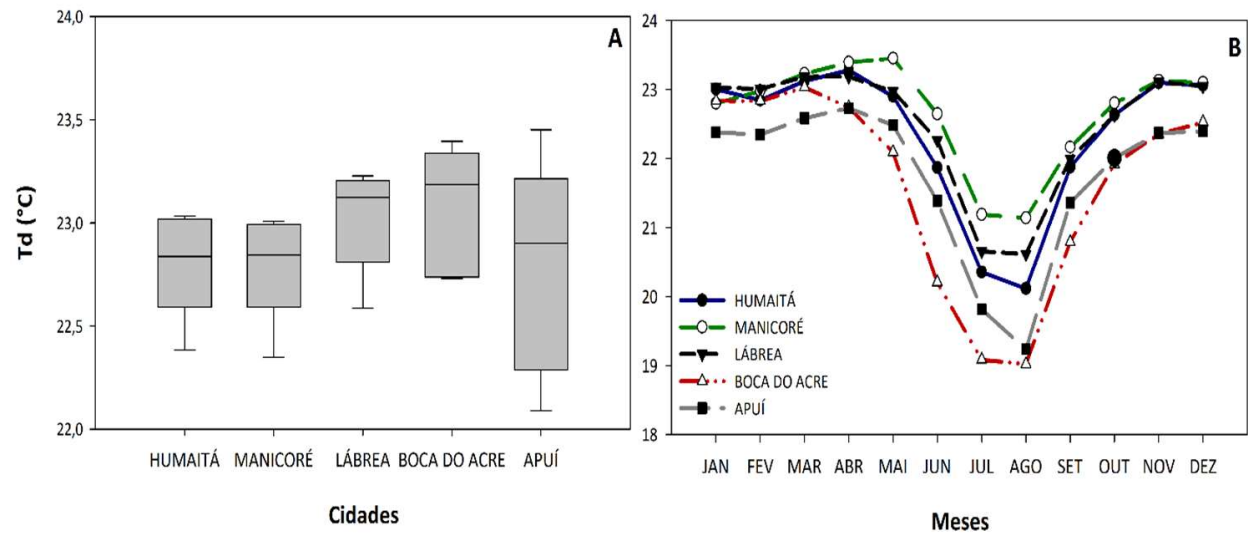

Figura 7: Box Plot da média anual da Temperatura do Ponto de Orvalho (Td) (A), e médias mensais Temperatura do Ponto de Orvalho (Td) (B), para o período de 2008 a 2018, contemplando os municípios de Humaitá, Manicoré, Lábrea, Boca do Acre e Apuí localizados na mesorregião Sul do Amazonas.

Os máximos médios mensais foram de $23,4{ }^{\circ} \mathrm{C}$ em Manicoré, $23{ }^{\circ} \mathrm{C}$ em Humaitá e Lábrea, $22,8{ }^{\circ} \mathrm{C}$ Boca do Acre e $22,5^{\circ} \mathrm{C}$ em Apuí todos ocorreram no período chuvoso e transição (dezembro a maio). As menores Td ocorreram ainda no inverno austral (agosto). Boca do Acre e Apuí registraram a menor $\mathrm{Td} 19^{\circ} \mathrm{C}$. Já Humaitá, Lábrea e Manicoré obtiveram $20,5^{\circ} \mathrm{C} ; 20,8^{\circ} \mathrm{C}$ e $21,3^{\circ} \mathrm{C}$ respectivamente, ambas no período seco (junho a agosto) (Figura 7B).As máximas médias horárias ocorreram de janeiro a abril (verão - outono) chegaram a $23,8{ }^{\circ} \mathrm{C}$, sempre próximas do meio dia em todas as cidades, mas destaque para Manicoré que teve Td ligeiramente superior as outras em todos horários (Figura 8).As médias mínimas chegaram a $17{ }^{\circ} \mathrm{C}$ em agosto as $14 \mathrm{hs} \mathrm{e} 18{ }^{\circ} \mathrm{C}$ às $7 \mathrm{~h}$ em julho, ambas em Boca do Acre. Os meses de julho e agosto foram responsáveis pelos menores valores médios mínimos de toda serie, Apuí $17,2{ }^{\circ} \mathrm{C}$; Humaitá $18,2{ }^{\circ} \mathrm{C}$; Lábrea $19,8^{\circ} \mathrm{C}$; todas em agosto e Manicoré $\left(20,4{ }^{\circ} \mathrm{C}\right.$ ) em julho (Figura 8 ). Os meses de junho e julho apresentam maiores oscilações horárias em relação aos horários dos outros meses. Boca do Acre teve amplitude térmica de $1^{\circ} \mathrm{C}$ variando de $19^{\circ} \mathrm{C}$ as $00 \mathrm{~h}$ a $18^{\circ} \mathrm{C}$ às $7 \mathrm{~h}$, enquanto Apuí em agosto, obteve $20^{\circ} \mathrm{C}$ as $01 \mathrm{~h}$ e $17^{\circ} \mathrm{C}$ as $16 \mathrm{~h}$. 


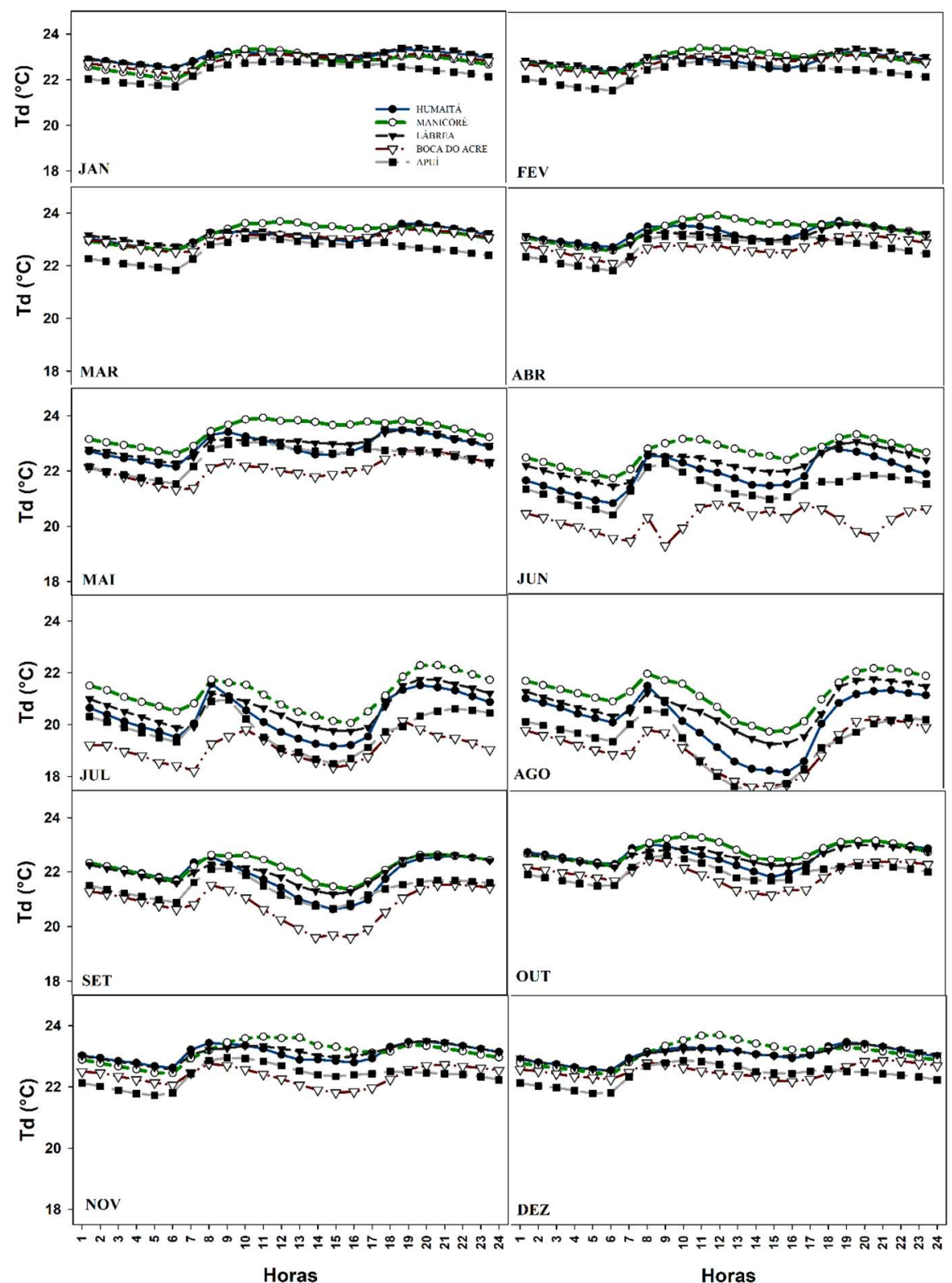

Figura 8: Médias horárias mensais da temperatura do ponto de orvalho (Td) para os anos de 2008 a 2018, para os municípios de Humaitá, Manicoré, Lábrea, Boca do Acre e Apuí, na mesorregião sul do Amazonas, Brasil.

Tabela 4: Estatística descritiva dos dados médios mensais de temperatura do ponto de orvalho a partir de abril de 2008 a abril de 2018. X̄m: Média Mensal ( $\left.{ }^{\circ} \mathrm{C}\right)$; EP: Erro Padrão; MD: Mediana; DP: Desvio Padrão; V: Variância; K:

Curtose; AS: Assimetria.

\begin{tabular}{|c|c|c|c|c|c|c|c|c|c|c|c|c|c|}
\hline & & Jan & Fev & Mar & Abr & Mai & Jun & Jul & Ago & Set & Out & Nov & Dez \\
\hline \multirow{7}{*}{ 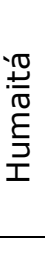 } & $\overline{\mathrm{X}} \mathrm{m}$ & 23,01 & 22,84 & 23,12 & 23,28 & 22,90 & 21,87 & 20,36 & 20,12 & 21,87 & 22,63 & 23,10 & 22,5 \\
\hline & MD & 23,01 & 22,85 & 23,15 & 23,31 & 23,07 & 22,10 & 20,80 & 20,49 & 21,99 & 22,68 & 23,14 & 22,6 \\
\hline & DP & 9,56 & 10,82 & 10,97 & 10,97 & 10,99 & 10,66 & 9,50 & 9,42 & 10,11 & 10,14 & 9,29 & 5,7 \\
\hline & $\mathrm{V}$ & 91,45 & 117,13 & 120,31 & 120,26 & 120,86 & 113,75 & 90,32 & 88,88 & 102,32 & 102,80 & 86,30 & 42,4 \\
\hline & EP & 0,05 & 0,06 & 0,06 & 0,05 & 0,07 & 0,10 & 0,14 & 0,14 & 0,08 & 0,06 & 0,05 & 0,3 \\
\hline & $K$ & $-0,07$ & 0,26 & 0,44 & 183,87 & 3,92 & 0,85 & 3,26 & 0,72 & 1,94 & 0,84 & 0,33 & 1,5 \\
\hline & As & $-0,10$ & $-0,10$ & $-0,09$ & $-0,23$ & $-1,00$ & $-0,84$ & $-1,46$ & $-0,83$ & $-0,83$ & $-0,35$ & $-0,28$ & 0,4 \\
\hline \multirow{7}{*}{$\begin{array}{l}\frac{0}{0} \\
\frac{0}{2} \\
\stackrel{\pi}{\Sigma}\end{array}$} & $\overline{\mathrm{X}} \mathrm{m}$ & 22,80 & 28,30 & 23,23 & 23,40 & 23,45 & 22,65 & 21,19 & 21,14 & 22,16 & 22,81 & 23,13 & 23,10 \\
\hline & $\mathrm{MD}$ & 22,95 & 23,01 & 23,26 & 23,45 & 23,48 & 22,82 & 21,61 & 21,59 & 22,29 & 22,85 & 23,14 & 23,13 \\
\hline & DP & 8,44 & 0,82 & 5,31 & 8,84 & 8,80 & 8,54 & 8,58 & 8,02 & 1,11 & 0,96 & 5,87 & 5,86 \\
\hline & $\mathrm{V}$ & 71,20 & 0,68 & 28,37 & 78,07 & 77,43 & 72,90 & 73,74 & 64,43 & 1,42 & 0,99 & 34,52 & 34,39 \\
\hline & EP & 0,04 & 0,06 & 0,06 & 0,07 & 0,06 & 0,09 & 0,15 & 0,14 & 0,08 & 0,07 & 0,07 & 0,06 \\
\hline & $\mathrm{K}$ & 5,23 & 0,01 & 0,09 & 1,89 & 0,30 & 0,37 & 1,15 & 0,62 & 0,78 & 0,55 & 0,36 & 0,32 \\
\hline & As & $-1,52$ & $-0,17$ & $-0,11$ & $-0,67$ & $-0,35$ & $-0,65$ & $-1,00$ & $-0,94$ & $-0,55$ & 16,22 & $-0,18$ & $-0,11$ \\
\hline \multirow{2}{*}{ ص } & $\overline{\mathrm{X}} \mathrm{m}$ & 22,84 & 22,83 & 23,03 & 22,74 & 22,09 & 20,21 & 19,09 & 19,02 & 20,79 & 21,92 & 22,36 & 22,53 \\
\hline & $\mathrm{MD}$ & 22,82 & 22,81 & 23,03 & 23,02 & 22,69 & 21,50 & 20,19 & 20,06 & 21,22 & 22,14 & 22,63 & 22,80 \\
\hline
\end{tabular}




\begin{tabular}{|c|c|c|c|c|c|c|c|c|c|c|c|c|c|}
\hline & $\mathrm{DP}$ & 9,26 & 9,66 & 9,65 & 10,24 & 10,50 & 9,33 & 9,20 & 8,71 & 8,50 & 6,85 & 5,74 & 6,39 \\
\hline & $\mathrm{V}$ & 87,77 & 94,62 & 93,82 & 105,23 & 110,28 & 87,20 & 84,77 & 75,97 & 72,53 & 49,00 & 40,00 & 48,17 \\
\hline & EP & 0,05 & 0,06 & 0,05 & 0,11 & 0,15 & 0,29 & 0,26 & 0,23 & 0,13 & 0,08 & 0,09 & 0,08 \\
\hline & $\mathrm{K}$ & 0,00 & 0,53 & 0,12 & 13,49 & 4,19 & 18,30 & 8,61 & 2,85 & 3,98 & 3,26 & 4,28 & 4,98 \\
\hline & As & $-0,02$ & $-0,10$ & 0,04 & $-2,85$ & $-1,94$ & $-3,59$ & $-2,31$ & $-1,54$ & $-1,59$ & $-1,22$ & $-1,61$ & $-1,80$ \\
\hline \multirow{7}{*}{ 言 } & $\overline{\mathrm{X}} \mathrm{m}$ & 22,38 & 22,35 & 22,59 & 22,73 & 22,48 & 21,39 & 19,82 & 19,24 & 21,36 & 22,01 & 22,37 & 22,40 \\
\hline & $\mathrm{MD}$ & 22,37 & 22,35 & 22,61 & 22,79 & 22,58 & 21,55 & 20,14 & 19,66 & 21,42 & 22,06 & 22,40 & 22,43 \\
\hline & DP & 4,65 & 7,64 & 9,27 & 8,53 & 8,40 & 8,05 & 7,15 & 5,39 & 2,54 & 3,18 & 4,38 & 4,50 \\
\hline & $\mathrm{V}$ & 29,48 & 59,94 & 86,73 & 73,99 & 71,71 & 65,23 & 51,46 & 29,11 & 8,70 & 13,25 & 24,52 & 28,43 \\
\hline & EP & 0,05 & 0,06 & 0,05 & 0,06 & 0,06 & 0,08 & 0,11 & 0,13 & 0,06 & 0,05 & 3,91 & 0,05 \\
\hline & $\mathrm{K}$ & $-0,03$ & 0,21 & 0,01 & 3,07 & 4,99 & 0,55 & 0,82 & $-0,37$ & 284,80 & 0,25 & 0,22 & 0,52 \\
\hline & As & $-0,02$ & $-0,05$ & $-0,16$ & $-0,80$ & $-1,36$ & $-0,59$ & $-0,88$ & $-0,61$ & 16,00 & $-0,27$ & $-0,20$ & $-0,17$ \\
\hline \multirow{7}{*}{ 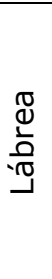 } & $\overline{\mathrm{X}} \mathrm{m}$ & 23,03 & 23,01 & 23,18 & 23,19 & 22,98 & 22,27 & 20,66 & 20,62 & 22,00 & 22,63 & 23,12 & 23,05 \\
\hline & MD & 23,04 & 23,01 & 23,19 & 23,29 & 23,18 & 22,49 & 21,25 & 21,26 & 22,20 & 22,68 & 23,13 & 23,05 \\
\hline & DP & 6,71 & 5,50 & 7,14 & 6,68 & 7,60 & 7,88 & 6,75 & 6,74 & 6,84 & 6,18 & 3,91 & 6,05 \\
\hline & $\mathrm{V}$ & 47,31 & 33,55 & 52,18 & 45,28 & 58,42 & 62,91 & 45,69 & 45,41 & 46,82 & 38,29 & 20,62 & 40,77 \\
\hline & EP & 0,05 & 0,05 & 0,05 & 0,06 & 0,08 & 0,09 & 0,14 & 0,14 & 0,10 & 0,05 & 0,05 & 0,04 \\
\hline & $\mathrm{K}$ & 0,00 & 0,20 & 0,17 & 8,76 & 11,04 & 1,98 & 3,29 & 1,44 & 3,69 & 0,93 & 0,24 & 0,33 \\
\hline & As & $-0,02$ & $-0,15$ & $-0,13$ & $-1,76$ & $-2,62$ & $-1,09$ & $-1,60$ & $-1,20$ & $-1,33$ & $-0,49$ & $-0,25$ & $-0,18$ \\
\hline
\end{tabular}

\section{DISCUSSÃO}

\section{Precipitação}

O período chuvoso compreendeu as estações de verão e outono ocasionado principalmente pela atuação dos sistemas de Monção da América do Sul, pela Zona de Convergência do Atlântico Sul (ZCAS) que se estende da Amazônia até o sudeste do País e causam grandes volumes de precipitação (Ppt), além da Alta da Bolívia (AB) (DANTAS, 2000; REBOITA et al., 2010). Alta da Bolívia (AB) é caracterizada como um anticiclone em altos níveis da troposfera (200 hPa). É resultante da convergência do ar mais aquecido e umidade em baixos níveis ( $850 \mathrm{hPa}$ ) e da divergência do ar que se resfria em altos níveis da atmosfera e varia de forma intra-sazonal e interanual (CHECHI et al., 2012).

O período seco ocorre na estação de inverno, onde registra-se altas temperaturas e baixa umidade. Durante o período seco, destaca-se a circulação da baixa troposfera que se move para o norte do cavado equatorial, proporcionando um deslocamento do ramo descendente da célula de Hadley sobre a Amazônia que inibe a formação de nuvens e consequentemente de chuvas nessa região (GALVANI et al., 2004; REBOITA et al., 2010; MAGANO JUNIOR et al., 2010; PEDREIRA JUNIOR et al., 2018).

O período de transição seco-chuvoso ocorre entre as estações de inverno e primavera (setembro) e ocorre devido ao início das atividades convectivas proporcionadas pelas altas temperaturas e incremento de umidade que possibilita a formação de Ppt (MONTEIRO et al., 2016). Durante a primavera ocorre a chegada dos sistemas frontais, início da atuação da Zona de Convergência Intertropical (ZCAS) e dos sistemas de Monção da América do Sul (SMAS), no sul do Amazonas que é responsável por grandes convecções, iniciando de fato o período chuvoso (GALVÃO et al., 2000; LOPES et al., 2016).

\section{Temperatura do ar (Tar)}

A ocorrência da maior Tar ocorre nos meses de agosto e setembro e está relacionado com a disponibilidade de radiação solar que chega a superfície, pois teve início o equinócio de primavera austral, 
neste período, o ângulo de incidência dos raios solares é menor para as latitudes locais, isso possibilita o menor caminho ótico para entrada de radiação solar (SILVA, 2008).

A Tar em toda mesorregião apresentou baixa amplitude anual $\left(4^{\circ} \mathrm{C}\right)$. $\mathrm{O}$ fato é comum em regiões próximas do Equador, pois recebem o ano inteiro altos índices de radiação solar. No entanto, essa variação é mais pronunciada na Amazônia meridional (Rondônia, Sul do Amazonas e Acre), em razão da penetração de frentes frias extratropicais, que recebem o nome de friagens, as quais chegam pelo sul do Brasil e são comuns na região durante a estação de inverno fazendo com que a amplitude anual seja superior as encontrados mais próximos do paralelo do Equador (CARVALHO et al., 2016; PEDREIRA JUNIOR et al., 2018). As friagens são mais pronunciadas em Boca do Acre em razão do seu relevo (Vale do Guaporé), que canaliza a entrada dessa massa de ar fria com maior intensidade, daí a maior discrepância de Tar, tanto em escala mensal como horaria para os outros municípios no mês de julho.

Outro fator que favorece a maior amplitude térmica nesse período é o balanço de radiação. No período diurno acontece a radiação e irradiação responsável pelo aumento da temperatura, já no período noturno ocorre apenas a irradiação, ou seja, o resfriamento noturno pela perda radiativa da superfície para a atmosfera (SILVA NETO et al., 2014).

Os resultados encontrados são corroborados por estudo feito nas cidades de Tefé e Manaus - AM, onde os autores encontraram resultados próximos, valores máximos médios diurnos de $31^{\circ} \mathrm{C}$ e $37^{\circ} \mathrm{C}$ às $14 \mathrm{~h}$ de mínimos de $25^{\circ} \mathrm{C}$ e $26^{\circ} \mathrm{C}$ às $6 \mathrm{~h}$, e amplitude térmica horaria de 6 e $11{ }^{\circ} \mathrm{C}$ dos municípios respectivamente (MONTEIRO et al., 2016; LOPES et al., 2016).

\section{Umidade relativa (UR)}

A umidade relativa é inversamente proporcional a Tar (CARVALHO et al., 2016), desta forma no período em que ocorre os maiores valores médios de Tar, observou-se que os menores de UR, na mesorregião isto ocorre em agosto. A UR é seguramente a forma mais conhecida de representar a presença do vapor de água na atmosfera e seu percentual, sob a temperatura que se encontra (REBOITA et al., 2010). A Umidade que ocorre na região está diretamente relacionada a três fatores; a precipitação, umidade trazida do oceano através dos ventos alísios e evapotranspiração (SANTOS et al.,2018).

A UR na mesorregião está diretamente relacionada a sazonalidade, no período chuvoso de outubro a abril observa-se seus maiores valores, já no período seco de junho a agosto registra-se os menores. Estes valores são corroborados por Carvalho et al. (2016). Os autores estudaram a umidade relativa em AriquemesRO e encontraram UR abaixo de 70\% no período seco. Quanto a variação horaria Reis et al. (2017) em Coari - AM, encontrou $60 \%$ dos seus dados menores, foram encontrados nos horários das 11 à $14 \mathrm{~h}$. Esta variação, em geral, não está associada à diminuição da quantidade de vapor do ar, mas sim à variação da temperatura durante o dia, com o aumento do potencial de evaporação durante a tarde (BLAIN et al., 2009; REBOITA et al.,2010; ROCHA et al.,2004).

A UR está interligada a diversos fatores, um deles é o grau de conforto humano sentido em determinadas situações, pois o aumento da temperatura do ar acarreta aumento da taxa de transpiração, 
cujo efeito é potencializado numa situação em que o ar já esteja seco (CHECHI et al., 2012). Em condições de ar quente e úmido, a evaporação do suor da superfície da pele é inibida pelo fraco potencial de pressão de vapor entre a pele e o ar ambiente (FOLHES et al., 2006). Já em condições de ar quente e seco, a evaporação do suor da superfície da pele é aumentada, conferindo condições, na maior parte das vezes, de maior conforto (MINAKI et al., 2013).

\section{Temperatura do Ponto de Orvalho (Td)}

A temperatura do ponto de orvalho (Td) é um importante variável a ser mensurada, pois a mesma funciona como o start para que ocorra a condensação (ROCHA et al., 2004). A Td sempre será menor ou igual a Tar, e quanto maior for a distância entre elas, menor será a UR. Quando a Td é inferior à Tar, significa que o ar não está saturado de vapor de água (a umidade relativa do ar é inferior a 100\%) (BUARQUE et al., 2010). Uma vez que ocorra a igualdade entre a Tar e a Td, o ar fica saturado de umidade (a umidade relativa do ar atinge $100 \%)$. A partir daí a Td passa a acompanhar a queda da Tar, que condensará na forma de gotículas de água, gerando o orvalho (MONTEIRO et al., 2016).

A quantidade máxima de vapor de água que se pode encontrar dissolvida em uma dada massa de ar é função da pressão e temperatura do sistema (BLAIN et al., 2009; BUARQUE et al., 2010). Temperaturas maiores implicam massas maiores de vapor admissíveis. Quando diminui a temperatura, a quantidade máxima de vapor de água admissível no sistema decresce, e a Td da massa de ar aumenta, mesmo mantendose a mesma massa de vapor dissolvida. Se a temperatura decrescer até que a quantidade máxima de vapor suportável irá se igualar à quantidade de vapor de água dissolvida na massa de ar, desta forma chegará 100\% a UR (ESPINOZA et al., 2011).

O ponto de orvalho depende de diversos fatores, entre outros, da umidade absoluta do ar, pois quando aumenta-se a quantidade de vapor de água dissolvido em uma dada massa de ar, eleva-se o ponto de orvalho (SIQUEIRA JUNIOR et al., 2015). Massas úmidas de ar têm pontos de orvalho superiores às massas de ar mais secas quando sob mesma pressão (DIAS et al., 2005).

\section{CONCLUSÕES}

De acordo com o comportamento das variáveis climatológicas, pode-se inferir que: O padrão climático de todas as variáveis está diretamente relacionado à sazonalidade, ou seja, variam de acordo com os períodos de maior e menor precipitação. A precipitação distribuiu-se em três fases: a chuvosa, contemplando os meses de outubro a abril, seca de junho a agosto e de transição com os meses de maio e setembro. Dentre as cidades do estudo Manicoré tem maior precipitação anual e Apuí menor.

A temperatura média do ar (Tar) mostrou que Boca do Acre é a cidade menos quente em relação aos outros municípios da mesorregião, sendo Humaitá a mais quente. Para todas as cidades a transição de inverno para a primavera foi o período mais quente. A temperatura do ponto de orvalho (Td), Boca do Acre novamente destaca-se por ter as menores temperaturas, ao passo que Manicoré registrou as maiores. A 
umidade relativa (UR), de forma geral foram altas. Os maiores valores ocorreram no período de maior precipitação, e Humaitá registrou as maiores médias, e as menores foram encontradas para Apuí.

Desta forma, ressalta-se que estudos futuros são importantes na mesorregião sul do Amazonas, com um período maior de dados de superfície de precipitação (Ppt), temperatura do ar (Tar), umidade relativa (UR) e temperatura do ponto de orvalho (Td), afim de propiciar um maior conhecimento destas variáveis e correlacioná-las com outras variáveis meteorológicas.

AGRADECIMENTOS: À CAPES pelo apoio concedido ao Programa de Pós-Graduação em Ciências Ambientais. À Fundação de Amparo à Pesquisa do Estado do Amazonas - FAPEAM pela concessão da bolsa de mestrado do primeiro autor através do Edital: RESOLUÇÃO N. 002/2016 - POSGRAD 2017 - UFAM. Ao Instituto Nacional de Meteorologia (INMET) pela disponibilidade dos dados.

\section{REFERÊNCIAS}

ALVARES, C. A.; STAPE, J. L.; SENTELHAS, P. C.; GONÇALVES, J. L. M.; SPAROVEK, G.. Köppen's climate classification map for Brazil. Meteorologische Zeitschrift, v.22, n.6, p.711-728, 2013. DOI: http://doi.org/101127/0941-2948/2013/0507

BLAIN, G. C.; PICOLI, M. C.; LULU, J.. Análises estatísticas das tendências de elevação nas séries anuais de temperatura mínima do ar no estado de São Paulo. Bragantia, v.68, n.3, p.807-815, 2009. DOI: http://dx.doi.org/10.1590/S0006$\underline{87052009000300030}$

BUARQUE, D. C.; CLARKE, R. T.; MENDES, C. A. B.. Spatial correlation. In: precipitation trends in the Brazilian Amazon. Journal of Geophysical Research, v.115, n.D11, 2010. DOI: http://doi.org/10.1029/2009JD013329

CARVALHO, R. L. S.; NASCIMENTO, B. I. S.; QUERINO, C. A. S.; SILVA, M. J. G.; DELGADO, A. R. S.. Comportamento das séries temporais de temperatura do ar, umidade e precipitação pluviométrica no município de Ariquemes (Rondônia-Brasil). Revista Brasileira de Climatologia, v.18, p.123-146, 2016. DOI: http://dx.doi.org/10.5380

CORREIA, M. F.; SILVA, F. S.; SILVA ARAGÃO, M. R. S.; SANTOS, E. P.; MOURA, M. S. B.. Impacto da expansão agrícola na amplitude térmica diária em ambiente semiárido. Ciência e Natura, v. Suplementar, p.311-314, 2011.

CHECHI, L.; BAYER, F. M.. Modelos Univariados de séries temporais para previsão das temperaturas médias mensais de Erechim, RS. Revista Brasileira de Engenharia Agrícola e Ambiental, v.16, n.12, p.1321-1329, 2012. DOI: http://dx.doi.org/10.1590/S1415-43662012001200009

DANTAS, R. T.; NÓBREGA, R. S.; CORREIA, A. M; RAO, T. V. R. Estimativas das temperaturas máximas e mínimas do ar em Campina Grande - PB. In: CONGRESSO BRASILEIRO DE METEOROLOGIA. Anais. Rio de Janeiro: SBMET, 2000.

DIAS, M. A. F. S.; COHEN, J. C. P. E.; GANDU, A. W.. Interações entre nuvens, chuvas e a biosfera na Amazônia. Acta amazônica, v.35, n.2, p.215-222, 2005. DOI: http://dx.doi.org/10.1590/S0044-59672005000200011
ESPINOZA, J. C.; RONCHAIL, J.; GUYOT, J. L.; JUNQUAS, C.; VAUCHEL, P.; LAVADO, W.; DRAPEAU, G.; POMBOSA, R.. Climate variability and extreme drought in the upper Solimões River (western Amazon Basin): Understanding the exceptional 2010 drought. Geophysical Research Letters, v.38, n.13, 2011. DOI: http://doi.org/10.1029/2011GL047862

FEARNSIDE, P. M.. Estoque e estabilidade do carbono nos solos na Amazônia Brasileira. In: TEIXEIRA, W. G.; MADARI, B. E.; BENITES, V. M.; KERN, D. C.; FALCÃO, N. P. S.. As Terras Pretas de Índio: Caracterização e Manejo para Formação de Novas Áreas. Belém: EMBRAPA, 2010.

FOLHES, M. T.; FISCH, G.. Caracterização climática e estudo de tendências nas séries temporais de temperatura do ar e precipitação em Taubaté (SP). Revista Ambi-Água, Taubaté, v.1, n.1, p.61-71, 2006.

GALVANI, E.; LUCHIARI, A.. Critérios para classificação de anos com regime pluviométrico normal, seco e úmido. In: SIMPÓSIO BRASILEIRO DE CLIMATOLOGIA GEOGRÁFICA, 6. Anais. Aracaju, 2004.

GALVÃO, J. A. C.; FISCH, G.. Balanço de energia em áreas de floresta e de pastagem na Amazônia (JI - Paraná, RO). Revista Brasileira de Meteorologia, São Paulo, v.15, n.2, p.25-37, 2000.

IBGE. Instituto Brasileiro de Geografia e Estatística. Amazonas. 2018.

INMET. Instituto Nacional de Meteorologia. Normais Climatológicas do Brasil 1961-1990. Brasília: INMET, 2009.

LOPES, J. S. G.; ALEIXO, N. C. R.; SILVA NETO, J. C. A.. Analise preliminar na temperatura e umidade relativa do ar em duas estações meteorológicas da cidade de Tefé-AM. In: SIMPÓSIO BRASILEIRO DE CLIMATOLOGIA GEOGRÁFICA, 12. Anais. Goiânia: UFG, 2016.

MACHADO, N. G.; QUERINO, C. A. S.; BIUDES, M. S.; DANELICHEN, V. H. M.; MARQUES, H. O.; PAVÃO, V. M.. Estimated net radiation in an Amazon-Cerrado transition 
forest by Landsat 5 TM. Journal of Applied Remote Sensing, v.11, p.1, 2017.

MAGANO JÚNIOR, H.; COSTA, A. C. L.; SILVA JÚNIOR, J. A.; SOUSA, J. R. A.; FEITOSA, J. R. P.; CUNHA, A. C.; SOUZA, I. M. P.. Sazonalidade da precipitação e umidade relativa do ar em cidades de diferentes portes na Região Amazônica Brasileira. Sociedade Brasileira de Meteorologia, v.1 p.1-5, 2010.

MARENGO, J. A.; LINCOLN, M.; ALVES, W.; SOARES, R.; RODRIGUEZ, D. A.; CAMARGO, H. R. M. P.; PABLO, A. D.. Two Contrasting Severe Seasonal Extremes in Tropical South America in 2012: Flood in Amazonia and Drought in Northeast Brazil. Journal of Climate, v.26, n.22, 2013.

MINAKI, C.; AMORIM, M. C. C. T.. Análise da temperatura e da umidade relativa do ar na primavera-verão em Araçatuba/SP. Revista Brasileira de Climatologia, Curitiba, v.13, n.9, p.236-247, 2013. DOI:

http://dx.doi.org/10.5380/abclima.v13i0.32976

MONTEIRO, J. C. R.; ARIDE, P. H. R.; OLIVEIRA, A. T.; SANTOS, S. M.; PANTOJA-LIMA, J.; HEYER, L. F.. Descrição da Temperatura e Umidade Relativa do Ar em distintas localidades da cidade de Manaus com diferentes geometrizações e espacialidades urbanas nos bairros do Parque Dez, Nova Cidade e bairro Centro - Manaus/Am. IGAPÓ, Revista de Educação Ciência e Tecnologia do IFAM, Manaus, v.10, n.1, p.25-45, 2016.

MENDONÇA, F.; OLIVEIRA, I. M. D.. Climatologia: Noções básicas e climas do Brasil. São Paulo: Oficina de textos, 2007.

NOGUEIRA, V. F. B.; CORREIA, M. F.; NOGUEIRA, V. S. Impacto do Plantio de Soja e do Oceano Pacífico Equatorial na Precipitação e Temperatura na Cidade de Chapadinha MA. Revista Brasileira de Geografia Física, Pernambuco, v.5, p.708-724, 2012.

PAVÃO, V. M.; NASSARDEN, D. C. S.; PAVÃO, L. L.; MACHADO, N. G.; BIUDES, M. S.. Impacto da Conversão da Cobertura Natural em Pastagem e Área Urbana sobre Variáveis Biofísicas no Sul do Amazonas. Revista Brasileira de Meteorologia, São Paulo, v.32, n.3, p.343-351, 2017. DOI: http://dx.doi.org/10.1590/0102-77863230002

PAVÃO, V. M.; QUERINO, C. A. S.; QUERINO, J. K. A. S.; MARTINS, P. A. S.; SIQUEIRA, L. F.; LEITE, L. O.; PASSOS, L. A.; COSTA, T. A. C. R.; MACHADO, N. G.; BIUDES, M. S.. Análise da radiação solar global $(\mathrm{rg})$ e albedo superficial sobre um ecossistema de floresta nativa em Humaitá - AM durante o período chuvoso. Revista EDUCAmazônia, Educação, Sociedade e Meio Ambiente, v.12, n.1, p.42-56, 2014.
PEDREIRA JUNIOR, A. L.; QUERINO, C. A. S.; QUERINO, J. K. A. S.; SANTOS, L. O. F.; MOURA, A. R. M.; MACHADO, N. G.; BIUDES, M. S.. Variabilidade horária e intensidade sazonal da precipitação no município de Humaitá-AM. Revista Brasileira de Climatologia, v.22, p.463-475, 2018. DOI: http://dx.doi.org/10.5380/abclima.v22i0.58089

REIS, G. P.; MORAES, E. O.. Variação da umidade relativa do ar no coração da floresta amazônica, um estudo de caso no município de coari (am) durante o ano de 2015. In: CONGRESSO NACIONAL DE GEOGRAFIA FÍSICA, 1. Anais. Campinas, 2017.

REBOITA, M. S.; GAN, M. A.; ROCHA, R.P. E.; AMBRIZZI, T. Regimes De Precipitação na América do Sul: Uma Revisão Bibliográfica. Revista Brasileira de Meteorologia, São Paulo, v.25, n.2, p.185-204, 2010.

RIVERO, S.; ALMEIDA, O.; ÁVILA, S.; OLIVEIRA, W.. Pecuária e desmatamento: uma análise das principais causas diretas do desmatamento na Amazônia. Nova Economia-Belo Horizonte, v.19, n.1, p.41-66, 2009. DOI: http://dx.doi.org/10.1590/S0103-63512009000100003

ROCHA, E. J. P.. Balanço de umidade e influência de condições de contorno superficiais sobre a precipitação da Amazônia. Tese (Doutorado) - Instituto Nacional de Pesquisas Espaciais, 2004

SALATI, E.; SANTOS, Â. A.; KLABIN, I.. Temas ambientais relevantes, Scielo estudos avançados, v.20 n.56, p.107-127, 2006.

SILVA NETO, J. C. A.; ALEIXO. N. C. R.. Análise Temporal da Terra e Cobertura Vegetal no Baixo Rio Tefé Amazonas. In: SIMPÓSIO LATINO AMERICANO DE GEOGRAFIA FÍSICA, 8. Anais. Tupã, 2014.

SILVA, F. R.. Estudo da radiação ultravioleta na cidade de Natal/RN. Dissertação (Mestrado em engenharia mecânica) - Universidade Federal do Rio Grande do Norte, Natal, 2008.

SANTOS, L. O. F.; QUERINO, C. A. S.; QUERINO, J. K. A. S.; BENTOLILA, L. B. V.; MARTINS, P. A. S.. validação dos dados de precipitação estimados pelo trmm no município de Lábrea/AM. In: SEMINÁRIO INTERNACIONAL EM CIÊNCIAS DO AMBIENTE E SUSTENTABILIDADE NA AMAZÔNIA, 5. Anais. Manaus, 2018.

SIQUEIRA JÚNIOR, J. L.; TOMASELLA, J.; RODRIGUEZ, D. A. Impacts of future climatic and land cover changes on the hydrological regime of the Madeira River basin. Climatic Change, v.129, n.1, p.117-129, 2015. DOI: http://doi.org/10.1007/s10584-015-1338-x

A CBPC - Companhia Brasileira de Produção Científica (CNPJ: 11.221.422/0001-03) detém os direitos materiais desta publicação. Os direitos referem-se à publicação do trabalho em qualquer parte do mundo, incluindo os direitos às renovações, expansões e disseminações da contribuição, bem como outros direitos subsidiários. Todos os trabalhos publicados eletronicamente poderão posteriormente ser publicados em coletâneas impressas sob coordenação da Sustenere Publishing, da Companhia Brasileira de Produção Científica e seus parceiros autorizados. Os (as) autores (as) preservam os direitos autorais, mas não têm permissão para a publicação da contribuição em outro meio, impresso ou digital, em português ou em tradução. 